\title{
Criterios de Ranson y BISAP como predictores de complicaciones en pancreatitis aguda
}

\section{Ranson and BISAP criteria as predictors of complications in acute pancreatitis}

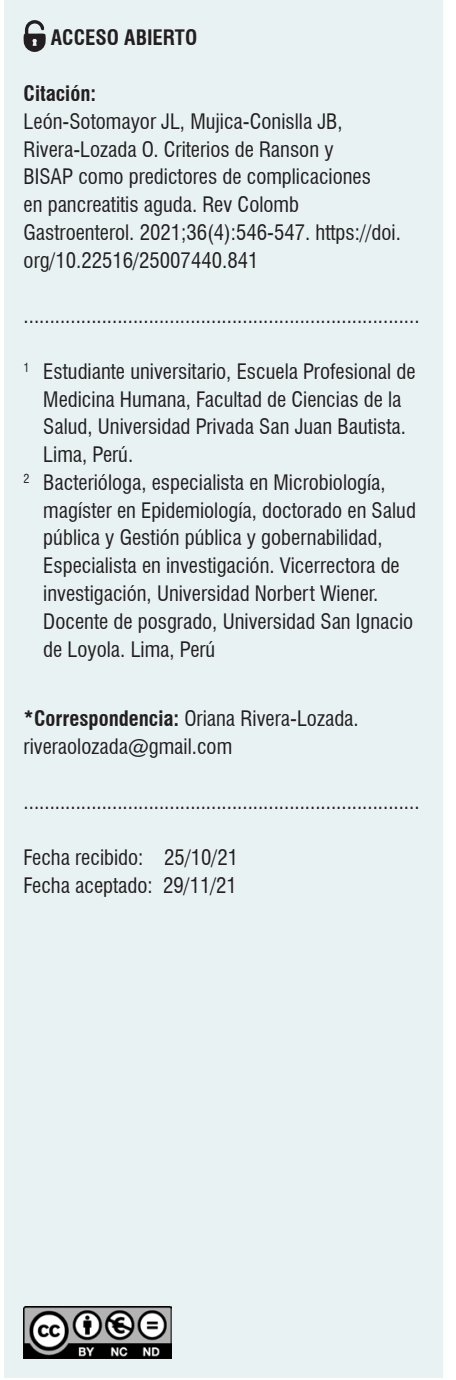

Estimado señor editor:

Hemos leído con gran interés el artículo publicado en su revista en el volumen 36, número 3, titulado "Características clínicas de pacientes con pancreatitis aguda atendidos en un hospital de alta complejidad en Cali”, de Arturo Rojas y colaboradores, en el que el propósito de la investigación fue conocer el comportamiento clínico de la pancreatitis aguda, teniendo en cuenta el factor demográfico, así como resaltar la causa biliar en esta enfermedad para poder realizar el diagnóstico diferencial. Este estudio permitió concluir que la pancreatitis aguda afecta a los adultos de todas las edades y se considera una urgencia.

En el estudio existen 2 importantes puntos que se requiere aclarar: uno de ellos es el título del artículo, en el que se mencionan solo las características clínicas. Se observa que en las variables han mencionado datos laboratoriales como la amilasa, la lipasa y datos imagenológicos como la tomografía axial computarizada (TAC), que a su vez tomó en cuenta a la clasificación de Balthazar; por tal razón, se considera que se debe incluir a los criterios de Ranson, que miden la gravedad de la pancreatitis aguda con base en el tiempo y más aún porque en la población de estudio hay pacientes adultos mayores que pueden ser evaluados con este criterio, ya que se tienen en cuenta la edad y el índice laboratorial ${ }^{(1)}$. Cuando se mencionan las complicaciones, lo ideal es que también se le incluya la insuficiencia pancreática exocrina, ya que esta complicación se manifiesta en 4 de cada 5 pacientes después de un debut de la pancreatitis aguda, por ello es importante medir las funciones pancreáticas con la prueba de secretina- colecistocinina (CCK), que detecta una leve secreción de las enzimas pancreáticas, y se debe tener en cuenta la prueba de secretina-CCK, también conocida como la ceruleína, que apoya el diagnóstico por su alta sensibilidad ${ }^{(2)}$.

El segundo punto a aclarar es que se requiere valorar la mortalidad con los criterios de APACHE II y Atlanta en el presente artículo. Así mismo, sería importante que se abarque el criterio de BISAP (índice clínico de gravedad en pancreatitis aguda), ya que incluye el estado mental y en esta investigación se incluye una población adulta mayor, por lo que es necesario tener en cuenta la escala de Glasgow como parte de la evaluación de la salud mental en el paciente ${ }^{(3)}$.

En conclusión, los criterios de APACHE II y Atlanta evalúan con más especificidad la gravedad en los pacientes, ya que es un buen pronóstico de mortalidad. Esperamos que estas observaciones se puedan tener en cuenta para un mejor panorama en futuras inves- 
tigaciones similares en las que se quiera abarcar los aspectos clínicos, clasificaciones o puntaje de la pancreatitis.

\section{Contribución de los autores}

Todos los autores concibieron la carta al editor, contribuyeron a la elaboración del mismo y aprobaron la versión final.

\section{Fuente de financiación}

Ninguna.

\section{Conflictos de interés}

Los autores declaran no tener ningún conflicto de interés.

\section{REFERENCIAS}

1. Li Y, Zhang J, Zou J. Evaluation of four scoring systems in prognostication of acute pancreatitis for elderly patients.

BMC Gastroenterol. 2020;20(1):165.

https://doi.org/10.1186/s12876-020-01318-8

2. Lee PJ, Papachristou GI. New insights into acute pancreatitis. Nat Rev Gastroenterol Hepatol. 2019;16(8):479-496. https://doi.org/10.1038/s41575-019-0158-2
3. Mederos MA, Reber HA, Girgis MD. Acute Pancreatitis: A Review. JAMA. 2021;325(4):382-390.

https://doi.org/10.1001/jama.2020.20317 